\title{
Simulation of Wind Turbine Driven Autonomous Squirrel Cage Induction Generators
}

\author{
Loránd SZABÓ, Károly Ágoston BIRÓ, Cosmina NICULA, Florin JURCA \\ Department of Electrical Machines, Technical University of Cluj \\ 400750 Cluj, P.O. Box 358, Romania \\ E-mail: Lorand.Szabo@mae.utcluj.ro
}

\begin{abstract}
Due to increased emphasis on renewable resources, the development of suitable isolated power generators driven by energy sources such as wind, small hydro-electric, biogas, etc. have recently assumed greater significance. The capacitor self-excited squirrel cage induction generator has emerged as a suitable candidate of isolated electrical power sources. In this paper such a system is studied both by means of laboratory tests and by simulation.
\end{abstract}

\section{INTRODUCTION}

The wind is a free, clean, and inexhaustible energy source, being simply air in motion. It is caused by the uneven heating of the earth's surface by the sun. Since the earth's surface is made of very different types of land and water, it absorbs the sun's heat at different rates.

Since ancient times the wind served mankind well for many centuries. Over 5000 years ago, the ancient Egyptians already used wind to sail ships on the Nile River. Later, people built windmills to grind wheat and other grains. The earliest known windmills were in Persia (Iran). Centuries later, the people of Holland improved the basic design of the windmill. They gave it propeller-type blades, still made with sails. American colonists used windmills to grind wheat and corn, to pump water, and to cut wood at sawmills. As late as the $1920 \mathrm{~s}$, Americans used small windmills to generate electricity in rural areas without electric service. When power lines began to transport electricity to rural areas in the $1930 \mathrm{~s}$, local windmills were used less and less, though they can still be seen on some Western ranches.

The oil shortages of the 1970s changed the energy picture for the entire world. It created an interest in alternative energy sources, paving the way for the re-entry of the windmill to generate electricity. In the early 1980s wind energy really took off all around the world, partly because of state policies that encouraged renewable energy sources.

In the last decades everybody understood that only new and renewable energy sources can guarantee a sustainable power production in the future for the mankind. Our future life on the Earth will be largely determined by how the required energy will be generated and how the technological innovation will be applied. The renewable energy sources surely will have a strong transformative effect on the whole of society in the coming decades. By virtually all accounts, renewable energy resources will be an increasingly important part of the power generation mix over the next several decades.
The clean technologies help reduce global carbon emissions, but they also add some much-needed flexibility to the energy resource mix by decreasing the dependence on limited reserves of fossil fuels.

Thanks to extensive R\&D efforts wind power has become the world's fastest growing energy source in $20^{\text {th }}$ century and has maintained this status until now. The wind energy become a reliable and competitive means for electric power generation. The life span of modern wind turbines is now about 20-25 years, which is comparable to many other conventional power generation technologies.

The cost of wind power has continued to decline through technological development, increased production level, and the use of larger turbines. The average capacity of new wind turbines deployed grew and the average installed capacity cost fell [1].

The total installed wind power capacity round the world at the end of 2006 stands over $74 \mathrm{GW}$. Only three countries share over the $59 \%$ of the total market: Germany $27.8 \%$, Spain $15.6 \%$ and US $15.6 \%$. These countries together have $43.84 \mathrm{GW}$ installed capacity. In 2006 only in the EU near $7.6 \mathrm{GW}$ of wind power capacity was installed, worth over 9 billion $€$. This means an increase of $23 \%$ compared to 2005 [2], [3].

Romania is between the rearguards in Europe concerning installed wind power capacity, having yet only $3 \mathrm{MW}$. Therefore a lot of thing can be done here in this field.

Due to this major interest for wind energy power plants intensive researches are done in numerous research centres all around the world. Hence any new results which contribute to the better understanding in this field could be of real interest for all the specialists.

\section{ThreE-Phase SQuirRel Cage Induction Generators}

Squirrel cage induction machines operating as autonomous generators from renewable energy sources have received much attention recently. Autonomous induction generators are cheap, simple and robust. However, while they are capable to generate active power, they are unable to produce the reactive power needed for their own excitation [4].

The classical solution to this problem is to connect capacitors across its stator terminals of the externally driven three-phase squirrel cage induction machine, as shown in Fig. 1. 


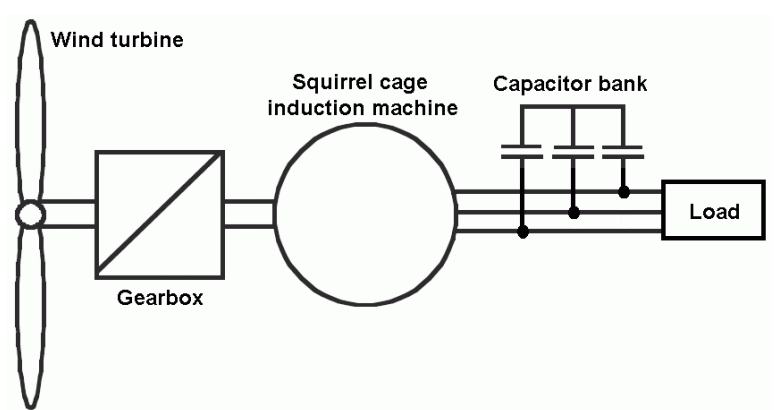

Fig. 1. Autonomous wind power system with squirrel cage induction generator

Due to the three-phase capacitor bank connected to the induction generator an emf is induced in the machine windings due to the self excitation provided by the capacitors. The magnetizing requirement of the machine is supplied by these capacitors. For self excitation to occur, the following two conditions must be satisfied [5]:

i.) The rotor of the machine should have sufficient residual magnetism.

ii.) The three-phase capacitor bank should be of sufficient value.

If an appropriate capacitor bank is connected across the terminals of an externally driven squirrel cage induction generator, and if its rotor has sufficient residual magnetism emf will be induced in the machine windings due to the excitation provided by the capacitors. This phenomenon is known as "capacitor self-excitation". If the induced emf is sufficient, leading currents through the capacitors will circulate.

The magnetic flux produced due to these currents would assist the residual magnetism in magnetising the iron core of the induction generator. This would increase the machine main magnetic flux and larger emf will be induced. This in turn will increase both the currents and the flux. The induced voltage and the current will continue to rise until the reactive power supplied by the capacitors is balanced by the reactive power required by the induction machine, a condition which is essentially decided by the saturation of the magnetic cores. This process is thus cumulative and the induced voltage keeps on rising until saturation is reached [5].

The squirrel cage induction generator having a capacitor bank connected to its terminal can be used autonomously or connected to the grid by adequate power electronic devices.

In the case when it is connected to the grid an uncontrolled diode bridge rectifier or a naturally commutated thyristor converter can be connected at the machine terminals, since the capacitors can provide the necessary reactive power for their operation. The network-side inverter can also be a simple line-commutated thyristor bridge. Such a scheme, however, is not favoured in practice due to the complexity introduced by the self-excitation of the induction generator and resonance problems, particularly in the lower speed region.

In the paper only the autonomous squirrel cage induction generator having a three-phase capacitor bank connected to its terminal will be discussed.
The stand-alone self-excited induction generator is for long time frequently used to supply for ordinarily growing energy demand loads in mainly rural areas owing to many economical advantages.

Thus, multiple generators operating in parallel may be required to harvest the maximum energy available at a site. Also, in the last few years, the trend has shifted from installing a few wind turbines to planning large wind farm installations with many induction generators connected electrically in parallel. Hybrid power plants that integrate wind farms with diverse storage devices to allow for the control of the power output of the ensemble further support the possibility of large-scale installations [6].

The main drawback of the autonomous squirrel cage induction generator having a three-phase capacitor bank is the lack of ability to control the terminal voltage and frequency under non-constant load and speed conditions. Therefore, capacitor excited induction generators have poor voltage and frequency stability [7].

To regulate the voltage of an autonomous induction generator with changing load and speed, the capacitors may be replaced or supplemented with an active external source of reactive power [8]. Such a so-called solid-state synchronous voltage source is based on a dc-ac converter (or inverter), which is able to generate leading or lagging reactive power. Thus, inverters can be used as reactive power compensators for squirrel cage induction generators [7]. Such a generator setup is given in Fig. 2.

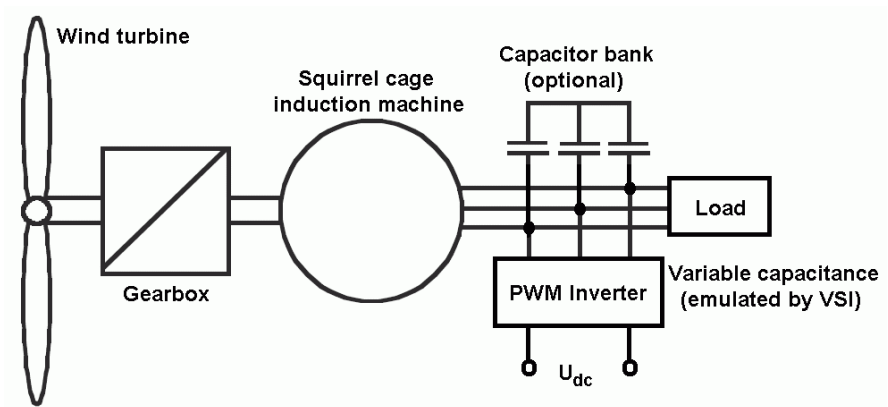

Fig. 2. Wind power system with squirrel cage induction generator using reactive power compensator

\section{The LABORATORy TeSts Performed With ThE SQUIRREL CAGE INDUCTION GENERATOR}

Several laboratory tests were performed using the squirrel cage induction machine from the Electrical machines Laboratory of the Technical University of Cluj.

The performed laboratory tests had two goals:

i.) To estimate the parameters of the squirrel cage induction machine in study in order to use them in the simulation programs.

ii.) To obtain result that could be compared later with those computed via simulation in order to validate the mathematical model of the machine.

The squirrel cage induction machine in study had the following main data: 
i.) Type: AST 1129284

ii.) Rated power: $3 \mathrm{~kW}$

iii.) Rated voltage: $220 / 380 \mathrm{~V}(\Delta / \mathrm{Y})$

iv.) Rated current: $11.4 / 6.61 \mathrm{~A}(\Delta / \mathrm{Y})$

v.) Rated speed: $14301 / \mathrm{min}$.

The laboratory setup is given in Fig. 3. The induction generator in study was rotated by a dc motor connected to its shaft.

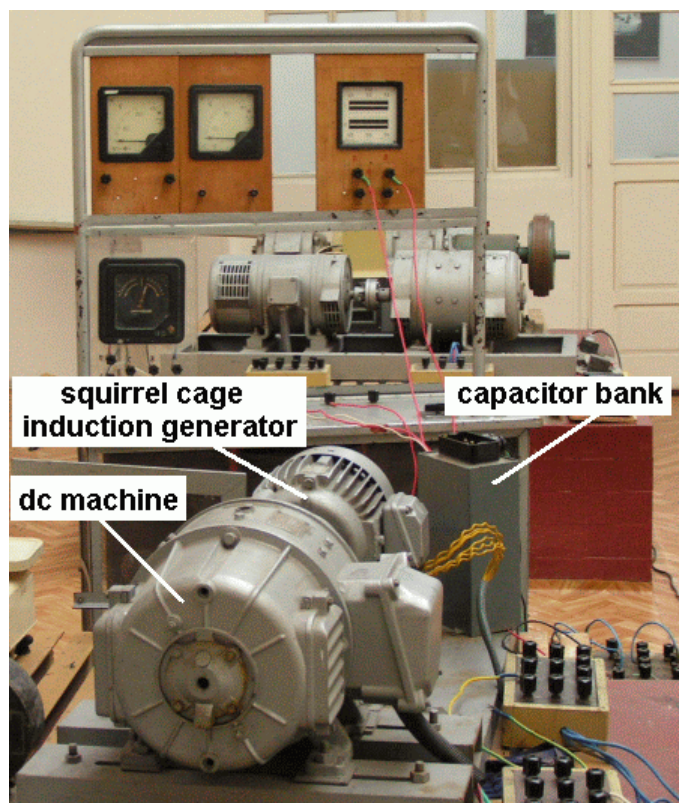

Fig. 3. The laboratory setup used for testing the squirrel cage induction generator

The electrical scheme of the test bench is given in Fig. 4.

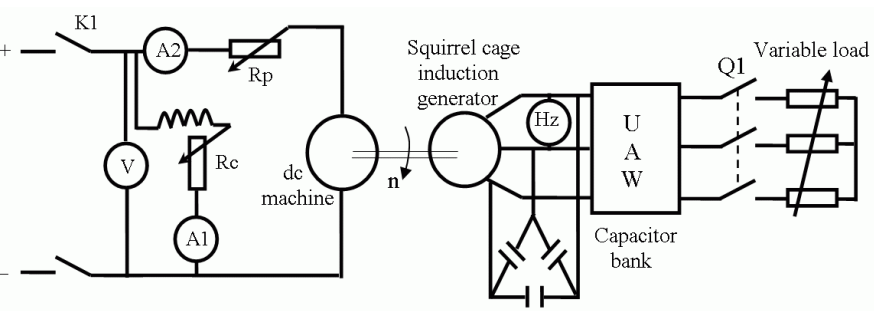

Fig. 4. The electrical scheme of the test bench

In order to estimate the main parameters of the squirrel cage induction machine in study two types of tests were performed: the no-load test and the short circuit test. Using the well-known formulas the resistances and the leakage inductances of the stator, respectively of the rotor were computed upon the results obtained via the two tests:

$$
\begin{gathered}
R_{s}=1.7 \Omega ; \quad R_{r}=1.79 \Omega \\
L_{s \sigma}=11.4 \mathrm{mH} ; \quad L_{r \sigma}=12 \mathrm{mH}
\end{gathered}
$$

(all the rotor quantities are referred to the stator of the machine).

Also based on the laboratory tests the variation of the magnetising inductances versus the magnetising current was established. The theoretical shapes of the total magnetising flux $\left(\lambda_{m}\right)$, and the magnetising inductances are given in Fig. 5.

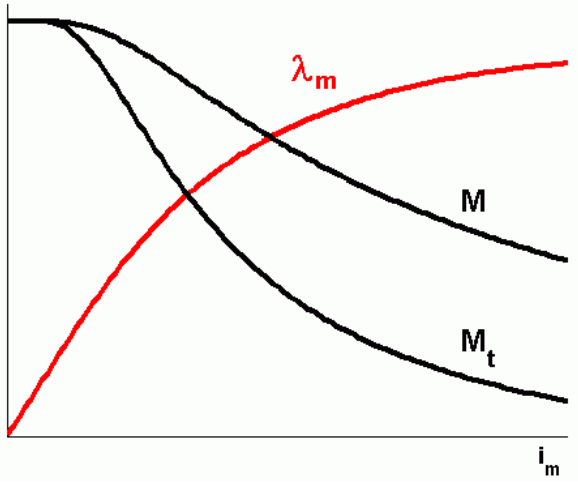

Fig. 5. The variation of the magnetising flux and inductances versus the magnetising current

By fitting a curve to the points obtained by measurements the $\lambda_{m}=f\left(i_{m}\right)$ function was plotted. The magnetising inductance and its dynamic (transient) variant were obtained from the above function using the following equations:

$$
M=\frac{\lambda_{m}}{i_{m}} ; \quad M_{t}=\frac{d \lambda_{m}}{d i_{m}}
$$

The variations of the two types of magnetizing inductances function of the magnetizing current are given in Fig. 6 .

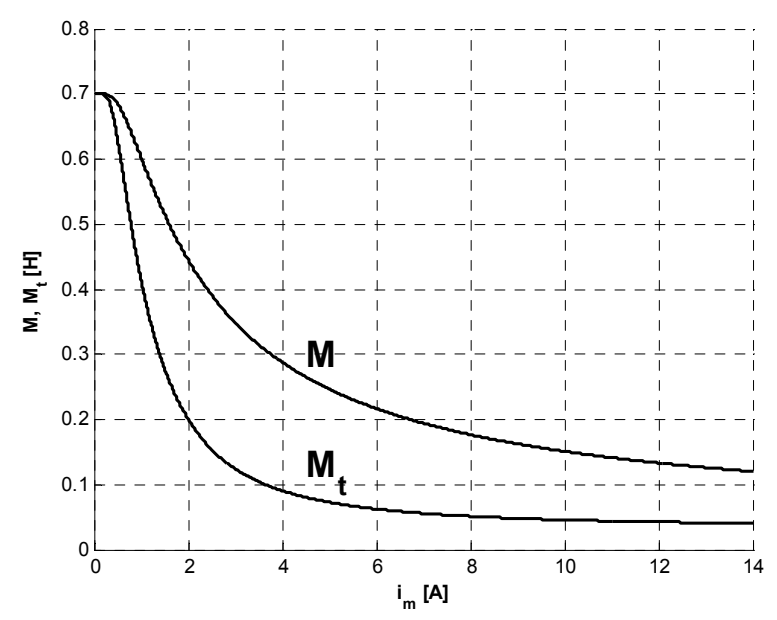

Fig. 6. The plots of the magnetizing inductances versus the magnetizing current

The other results of the laboratory tests will be given later, when they will be compared with the results obtained by simulations.

\section{The Mathematical Model Of The Squirrel Cage INDUCTION GENERATOR}

The first step towards the dynamic simulation of the wind turbine driven autonomous squirrel cage induction generators was to build up the mathematical model of the electrical machine.

The widely used $d-q$ reference frame was chosen to model the generator. In this case both the three-phased stator and squirrel cage of the rotor were transformed in two orthogonal axis systems upon Park's transformation (as shown in Fig. 7) 


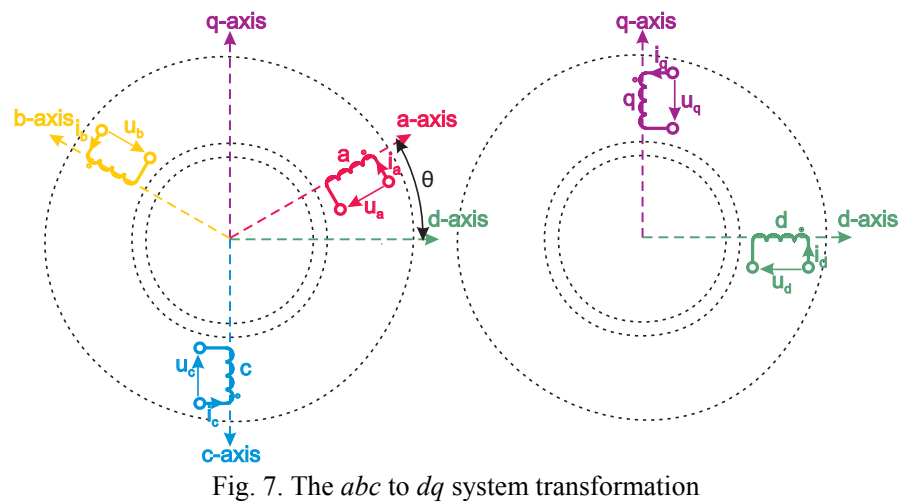

Hence the model machine has only 4 windings in quadrature (two on the stator and two on the rotor). The fixed reference frame was selected for writing the equations. Hence the angular speed of the reference frame in this case will be $\omega_{c}=0$.

For the stator windings the generator convention will be used, and for rotor windings the load one. The saturation effect of the magnetic cores also will be taken into account. Using the above conditions the following set of voltage equations results for the four windings:

$$
\begin{gathered}
u_{d}=-R_{s} i_{d}-\frac{d \lambda_{d}}{d t} ; \quad u_{q}=-R_{s} i_{q}-\frac{d \lambda_{q}}{d t} \\
u_{D}=R_{r} i_{D}+\frac{d \lambda_{D}}{d t}+\omega \lambda_{Q} ; \quad u_{Q}=R_{r} i_{Q}+\frac{d \lambda_{Q}}{d t}-\omega \lambda_{D}
\end{gathered}
$$

where $u$ is the voltage, $R$ the resistance, $i$ the current, $\omega$ the rotor electrical angular velocity, and $\lambda$ is the flux linkage. The $d$ and $q$ indices indicate the direct and quadrature axis components. With uppercase are marked the rotor quantities The $s$ and $r$ indices refers to the stator and rotor quantities, respectively. It should be mentioned again that all the rotor quantities are referred to the stator of the machine.

To be able to solve the problem another set of equations is required, the flux-current equations, written also for all the four windings:

$$
\begin{array}{ll}
\lambda_{d}=L_{s \sigma} i_{d}+M\left(i_{d}+i_{D}\right) ; & \lambda_{q}=L_{s \sigma} i_{q}+M\left(i_{q}+i_{Q}\right) \\
\lambda_{D}=L_{r \sigma} i_{D}+M\left(i_{d}+i_{D}\right) ; & \lambda_{Q}=L_{r \sigma} i_{Q}+M\left(i_{q}+i_{Q}\right)
\end{array}
$$

where $L_{S \sigma}$ and $L_{r \sigma}$ are the leakage inductances, respectively $M=M_{d}=M_{q}$ is the main magnetizing inductance.
The mathematical model of the generator must be completed by to equations due to the load and of the capacitors connected on its terminals.

The voltage equations of the load are the following:

$$
u_{d}=R_{l} i_{l_{d}}+L_{l} \frac{d i_{l_{d}}}{d t} ; \quad u_{q}=R_{l} i_{l_{q}}+L_{l} \frac{d i_{l_{q}}}{d t}
$$

where $R_{l}$ and $L_{l}$ are the resistance and inductance of the load, respectively $i_{l_{d}}$ and $i_{l_{q}}$ are the two orthogonal components of the load current.

The voltage equations of the condenser bank are:

$$
\begin{gathered}
u_{d}=\frac{1}{C} \int i_{C_{d}} d t ; \quad u_{q}=\frac{1}{C} \int i_{C_{q}} d t \\
i_{C_{d}}=i_{d}-i_{t_{d}} ; \quad i_{C_{q}}=i_{q}-i_{t_{q}}
\end{gathered}
$$

where $i_{C_{d}}$, respectively $i_{C_{q}}$ are the two orthogonal components of the current through the capacitor, and $C$ is the capacitance of the condenser.

Substituting the equations $(6) \div(7)$ of the magnetic fluxes into the voltage equations $(4) \div(5)$ and taking into account the leakage inductances $\left(L_{s \sigma}\right.$, respectively $\left.L_{r \sigma}\right)$ are constant the following system of differential equation is obtained after some simple computations:

$$
\left\{\begin{array}{r}
u_{d}=-R_{s} i_{d}-L_{s \sigma} \frac{d i_{d}}{d t}-\frac{d}{d t}\left[M\left(i_{d}+i_{D}\right)\right] \\
u_{q}=-R_{s} i_{q}-L_{s \sigma} \frac{d i_{q}}{d t}-\frac{d}{d t}\left[M\left(i_{q}+i_{Q}\right)\right] \\
0=R_{r} i_{D}+L_{r \sigma} \frac{d i_{D}}{d t}+\frac{d}{d t}\left[M\left(i_{d}+i_{D}\right)\right]+ \\
+\omega L_{r \sigma} i_{Q}+\omega M\left(i_{q}+i_{Q}\right) \\
\begin{array}{r}
0=R_{r} i_{Q}+L_{r \sigma} \frac{d i_{Q}}{d t}+\frac{d}{d t}\left[M\left(i_{q}+i_{Q}\right)\right]- \\
-\omega L_{r \sigma} i_{D}-\omega M\left(i_{d}+i_{D}\right)
\end{array}
\end{array}\right.
$$

Some simple computations lead to the final system of equations, which is practically the mathematical model of the squirrel cage induction generator written for a fixed $d-q$ reference system:

$$
\begin{gathered}
\frac{d i_{d}}{d t}=\frac{-u_{d}\left(L_{r \sigma}+M_{t}\right)-R_{s}\left(L_{r \sigma}+M_{t}\right) i_{d}+\omega M M_{t} i_{q}+R_{r} M_{t} i_{D}+\omega M_{t}\left(L_{r \sigma}+M\right) i_{Q}}{\Delta} \\
\frac{d i_{q}}{d t}=\frac{-u_{q}\left(L_{r \sigma}+M_{t}\right)-\omega M M_{t} i_{d}-R_{s}\left(L_{r \sigma}+M_{t}\right) i_{q}-\omega M_{t}\left(L_{r \sigma}+M\right) i_{D}+R_{r} M_{t} i_{Q}}{\Delta} \\
\frac{d i_{D}}{d t}=\frac{u_{d} M_{t}+R_{s} M_{t} i_{d}-\omega M\left(L_{s \sigma}+M_{t}\right) i_{q}-R_{r}\left(L_{s \sigma}+M_{t}\right) i_{D}-\omega\left(L_{S \sigma}+M_{t}\right)\left(L_{R \sigma}+M\right) i_{Q}}{\Delta} \\
\frac{d i_{Q}}{d t}=\frac{u_{q} M_{t}+\omega M\left(L_{s \sigma}+M_{t}\right) i_{d}+R_{s} M_{t} i_{q}+\omega\left(L_{r \sigma}+M\right)\left(L_{s \sigma}+M_{t}\right) i_{D}-R_{r}\left(L_{s \sigma}+M_{t}\right) i_{Q}}{\Delta}
\end{gathered}
$$

where: 


$$
\Delta=L_{s \sigma} L_{r \sigma}+L_{s \sigma} M+L_{r \sigma} M
$$

The mathematical model must be completed with the equations of the load, respectively of the capacitors connected to the terminal of the squirrel cage induction generator, also brought to a differential form:

$$
\begin{gathered}
\frac{d i_{l_{d}}}{d t}=\frac{u_{d}-R_{l} \cdot i_{l_{d}}}{L_{l}} ; \quad \frac{d i_{l_{q}}}{d t}=\frac{u_{q}-R_{l} \cdot i_{l_{q}}}{L_{l}} \\
\frac{d u_{d}}{d t}=\frac{i_{d}-i_{l_{d}}}{C} ; \quad \frac{d u_{q}}{d t}=\frac{i_{q}-i_{l_{q}}}{C}
\end{gathered}
$$

From the last equations the two orthogonal components of the terminal voltage $\left(u_{d}\right.$ and $\left.u_{q}\right)$ has to be extracted function of the stator current components $i_{d}$ and $i_{q}$, and substituted in equations $(12) \div(15)$ in order to obtain a practically usable system of equations.

The above presented mathematical was used for the simulation programs of the squirrel cage induction generators.

\section{Simulation Of The Squirrel Cage Induction GENERATOR}

Using the mathematical model of the squirrel cage induction generator the simulation program was built up in the combined MATLAB $^{\circledR} /$ SIMULINK $^{\circledR}$ environment, one of the best choices to simulate complex dynamic systems.

For easy understanding and using of the simulation program it was built up modularly, using several sub-systems. In the framework of the simulation program there are several switches back and forth between simulation in SIMULINK ${ }^{\circledR}$, respectively computation and visualization in MATLAB $^{\circledR}$, taking the full advantages of both programs.

The main window of the simulation program is given in Fig. 8 .

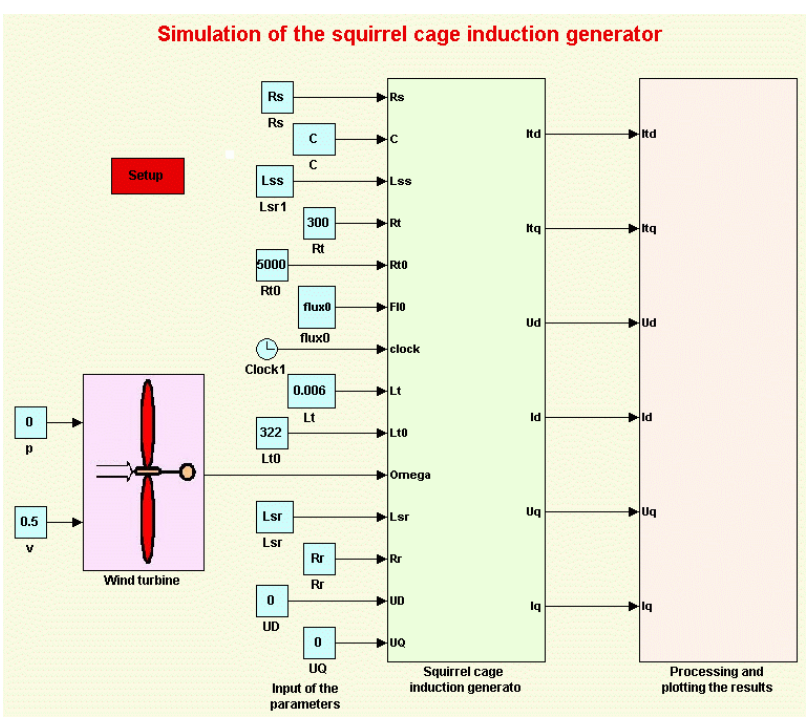

Fig. 8. The main window of the simulation program

Due to the lack of space here the subsystems of the model cannot be presented in detail.

All the data regarding the electrical energy generation system is loaded in the simulation program from an $m$-file by pressing the Setup button in the main window shown in Fig. 8.

The obtained results are saved in mat-type data files. The results can be plotted in various forms in MATLAB ${ }^{\circledR}$ upon the request of the user.

Next results of a single simulation will be presented. In this case the induction generator is rotated with its rated speed, $1500 \mathrm{l} / \mathrm{min}$. The generator is started at no-load, only after $1.5 \mathrm{~s}$ the load is coupled to the generator.

The main results of this simulation are given in Fig. 9. For better understanding of the results a zoom of the results is given in Fig. 10 for the first $1 \mathrm{~s}$ of working at no-load.

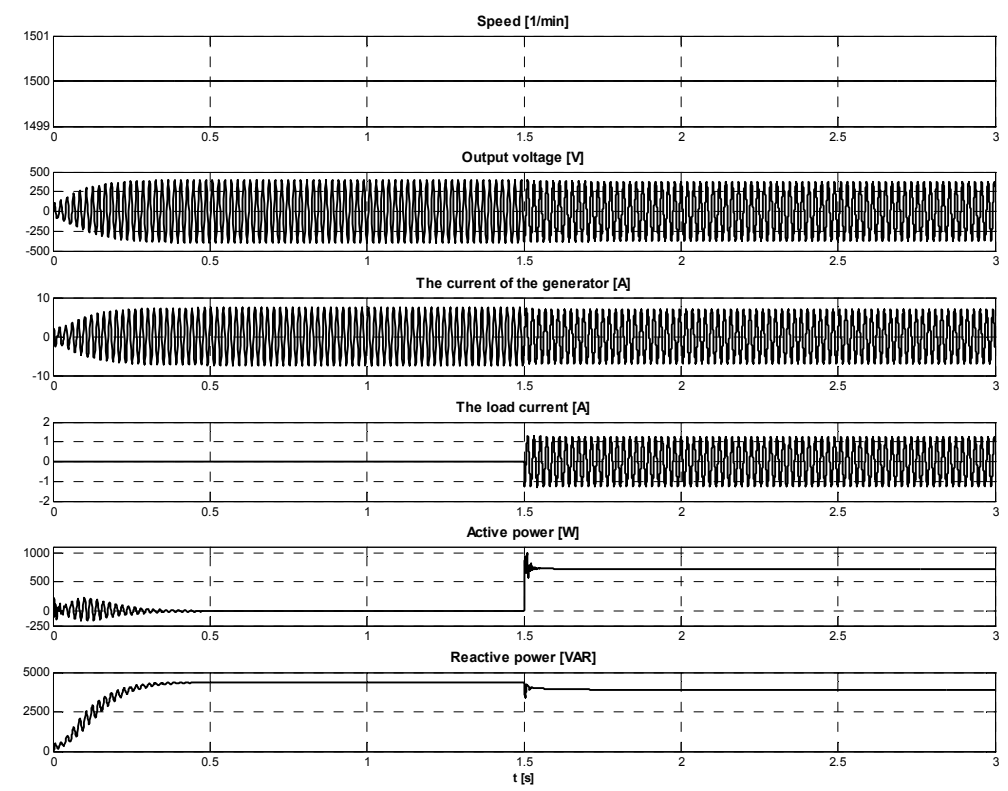

Fig. 9. The main results of the simulation 


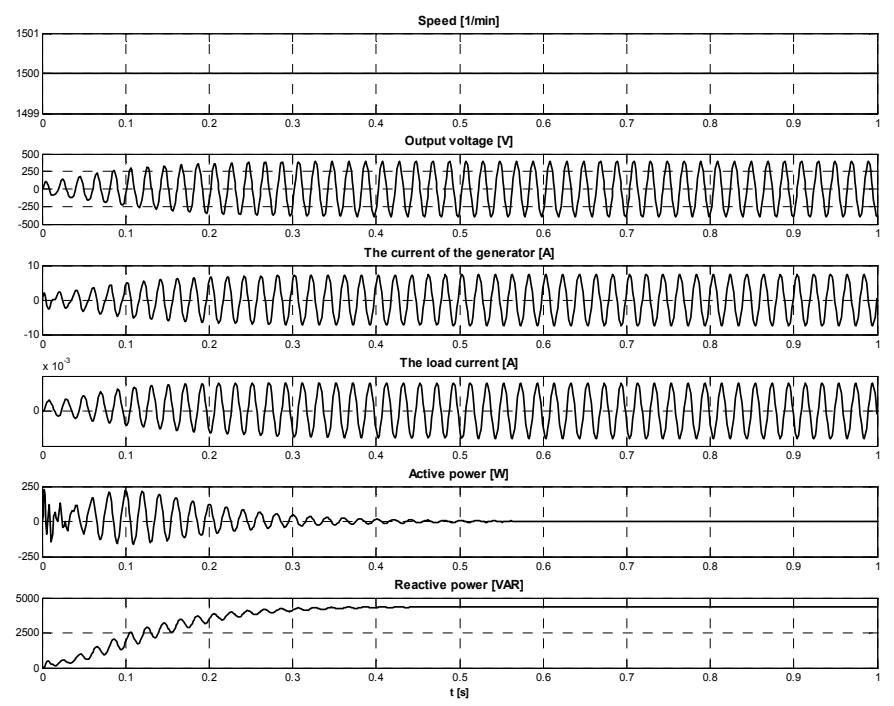

Fig. 10. The results during starting at no-load

Studying the figures it can be clearly seen the effect of coupling the load at $1.5 \mathrm{~s}$ : the load current appears, the active power produced by the induction generator is also increased. The reactive power, the terminal voltage and the current through the generator are a little bit decreased.

Next, in order to validate both the mathematical model, respectively the parameter estimation of the squirrel cage induction generator the results obtained via simulations and via laboratory test will be compared. The results presented in Fig. 11 are for the steady state regime when the generator was speeded up to its rated speed and in both cases the same load is coupled to its terminals.

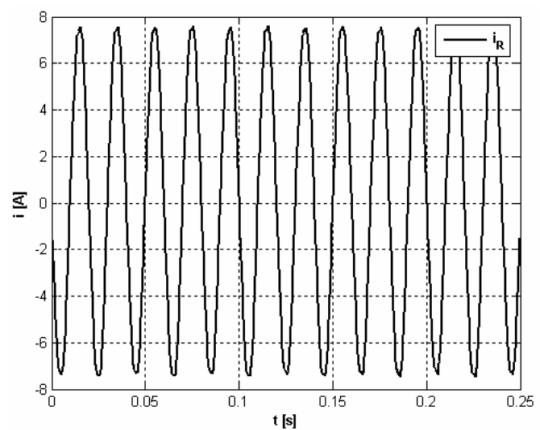

a) measured results

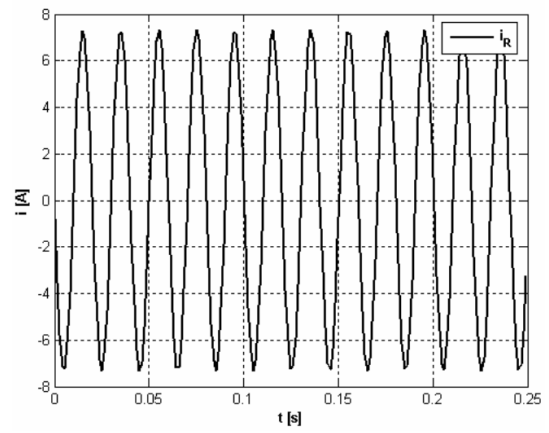

b) results obtained by simulations Fig. 11. Comparison of the results

As it can be seen the two sets of results are closed.

\section{CONCLUSIONS}

The mathematical model of the squirrel cage induction generator presented in details in this paper is a useful tool in studying the wind turbine driven autonomous electrical power generation systems. Its availability was proven by laboratory test.

The simulation program will be of real help in the future when the control system for the squirrel cage induction generator used in wind power plants will be designed. It will be also useful both in undergraduate and master level electrical engineering education.

\section{REFERENCES}

[1] Chang, L., "Wind Energy Conversion Systems," IEEE Canadian Review, Spring 2002, pp. 12-16.

[2] "Wind Power Installed in Europe by End of 2006 (Cumulative)," European Wind Energy Association (EWEA), Brussels (Belgium), 2007. URL: http://www.ewea.org/fileadmin/ewea documents/documents/ publications/statistics/070129 Wind map 2006.pdf.

[3] "Global wind energy markets continue to boom - 2006 another record year," Press release of Global Wind Energy Council (GWEC), Bruxelles (Belgium), 02.02.2007. URL: http://www.gwec.net/uploads/media/ 07-02_PR_Global_Statistics_2006.pdf.

[4] Seyoum, D., Rahman, M.F., and Grantham, C., "Terminal voltage control of a wind turbine driven isolated induction generator using stator oriented field control," Proceedings of the Eighteenth Annual IEEE Applied Power Electronics Conference and Exposition (APEC '03), Miami Beach (FL, USA), vol. 2, 2003, pp. 846-852.

[5] Kishore, A., Prasad, R.C.. and Karan, B.M., "MATLAB SIMULINK Based DQ Modeling and Dynamic Characteristics of Three Phase Self Excited Induction Generator," Proceedings of the Progress In Electromagnetics Research Symposium, Cambridge (USA), 2006, pp. 312-316.

[6] Palle, B., Simoes, M.G., and Farret, F.A., "Dynamic simulation and analysis of parallel self-excited induction generators for islanded wind farm systems," IEEE Transactions on Industry Applications, vol. 41, no. 4 (July-August 2005), pp. 1099-1106.

[7] Rabinovici, R., and Kuperman, A., "Autonomous induction generator with solid-state reactive power excitation," Proceedings of the $22^{n d}$ IEEE Conference In Israel, 2002.

[8] Valtchev, V., Van den Bossche, A., Ghijselen J., and Melkebeek, J., "Autonomous renewable energy conversion system," Renewable Energy, vol. 19, no. 1-2 (January 2000), pp. 259-275. 